\title{
OBSCENITY AS AN ESTHETIC CATEGORY
}

\author{
Abraham Kaplan*
}

My problem is not what to do about obscenity, but what to make of it. Control over the arts in this country-whether by official power or by unofficial influencerests largely on allegations of obscenity. But patterns of social control cannot reasonably be appraised without some conception of what it is that is being controlled. Accordingly, I ask what constitutes obscenity in relation to the arts: Can a work of art be obscene and still be esthetic in status and function? What part, if any, does the obscene play in the esthetic experience? What characteristics of the art object mark its occurrence?

These questions are meant as belonging to the philosophy of art, not to its psychology or sociology. To answer them is not to assert matters of fact, but to clarify relations of ideas. Such a clarification must take facts into account, of course-but its outcome, if successful, is a clear conception rather than a true proposition. Still less does an answer to these questions entail a social policy or a procedure for implementing policy. I do not pretend that the distinctions to be drawn in this essay can be directly applied in a court of law. I shall be content if they throw light on the problem of obscenity for the artist, his audience, and the critic who interprets each to the other.

\section{I}

Many people anxious to defend freedom of expression in the arts attack the suppression of obscenity on the grounds that obscenity has no objective existence, but is to be found only in the mind of the censor. I share the conclusion which this argument is intended to bolster-namely, that censorship is to be condemned; but the argument itself appears to me to be fallacious. Its premise is the undeniable proposition that judgments of the obscene vary with time and place. But from this true premise, the invalid inference is made to a subjectivist conclusion: All that can be common to such varying judgments is simply a subjective emotion of disapproval. "Obscenity exists only in the minds and emotions of those who believe in it, and is not a quality of a book or picture." To think otherwise, so this logic runs, is to be guilty of a superstition which is "the modern counterpart of ancient witchcraft."

Now those exercised over obscenity do perhaps resemble the old prosecutors of

* B.A. I937, Ph.D. I942, University of California at Los Angeles. Professor and Chairman of the Department of Philosophy, University of California at Los Angeles. Co-author (with Harold D. Lasswcll), Power AND SocietY (I950). Contributor to esthetic and philosophical periodicals.

1 Theodore Schroeder, Freedom of the Press and "Obscene" Literature 42 (1906); and "Obscene" Literature and Constitutional Law 13-I4 (I9I1).

${ }^{2}$ Morris l. Ernst and William Seagle, To the Pure . . . A Study of Obscenity and the Censon $\mathrm{x}$ (r928). 
witchcraft in their fanaticism and irrationality. ${ }^{3}$ The emphasis on the relativism of obscenity thus exposes the narrowness and rigidity of traditionalist morality. But the belief in witchcraft was simply false. The belief in obscenity is false only if its relational character is overlooked. What is superstitious is an absolutist conception, ${ }^{4}$ alleged to apply universally whether it be recognized or no. The alternative to absolutism is not subjectivism, but an insistence on objectivity relative to a specified context. The rationality of a belief is similarly relative to the evidence available for it. But this relation is not only compatible with objectivity, but even defines it. Such a standpoint has come to be known as objective relativism or contextualism. ${ }^{5}$

Judgments of obscenity vary because they are contextual. I mean more than that "dirt" is misplaced matter, i.e., that propriety varies with circumstances. I mean that obscenity is to be found in words or pictures only in so far as these can be interpreted to have a certain meaning; and meaning itself is contextual. D. H. Lawrence has protested against objectivism that "it is the mind which is the Augean stables, not language." But language has no content at all, obscene or otherwise, without mind. It means what it does only because it is interpreted as it is in definite contexts, and it is in just such contexts of interpretation that its obscenity is to be localized. So far as the facts of relativity are concerned, obscenity is no more subjective than is any esthetic quality whatever.

What is sound in the relativist position is preserved in the recognition of the difference between an art object and the work of art which results when the object is responded to in an esthetic context. The art experience is not a passive one, but requires the active participation of the respondent. And obscenity is a property of the resultant work and not of the object out of context. When people disagree whether something is obscene, they are likely to be judging different works of art (constructed, as it were, from the same object), rather than reacting differently to the same work. The important problem posed by relativism is, then, which work we are to judge when confronted with a particular art object: it is the problem of interpretation. Of course, standards of propriety may differ, just as there are differences in, say, what would amuse us and the Greeks. But when we read the comedies of Aristophanes, these differences either enter into the interpretation we give to the plays (the art objects), and so give rise to different works of art for us than for his contemporaries, or else the differences are not esthetically relevant at all. Once such differences are explicitly brought into the context, the relativism is objectified.

Now all art is essentially ambiguous, in the sense that the interpretation it calls for is an imaginative one. The object cannot be so fully specified as to leave no room in its reading for our own creative activity. ${ }^{7}$ But what allows for an imagina-

\footnotetext{
${ }^{3}$ See 2 Vilfredo Pareto, The Mind and Society roro (Livingston ed. 1935).

- Sce Morttaker J. Adler, Art and Prudence r26 (1937).

- Sce John Dewey, ARt as Experience (1934).

'D. H. Lawrence, Sex Literature and Censorship 59 (1953).

${ }^{7}$ See Kaplan and Kris, Esthetic Ambiguity, in Ernest Kris, Psychoanalytic Explorations in ART c. Io (1952).
} 
tive reading also makes possible a reading which is wholly our own projection. It is this danger, and not subjectivism, which is the point of the truism that "to the pure all things are pure." But not all interpretations are merely projective. The qualifications of the reader may make all the difference. A pure mind is just as likely to miss an entendre in Shakespeare as an ignorant one is to misread his Elizabethan usages. A proper judgment of obscenity in the arts can only be made by an informed and sensitive reader-not necessarily because only he can decide whether a work is obscene, but because only he can decide what work it is that is being judged.

I say a "proper" judgment, but more accurate is: a judgment made in the ideal context-ideal, that is, from the standpoint of esthetic appreciation and criticism. But there are other sorts of contexts in which a judgment might be made. There is the personal context, constituted by the judger himself. And there are various standard contexts (specified statistically or in other ways) which also occur and have their uses. Which context is to be chosen depends on the purpose for which the judgment is being made. I know of no principle of selection or evaluation apart from such purposes. To the question "Who is to judge whether a work is obscene?" we can reply only with the counter-questions, "What is to be done with the judgment when it is made? And why is it being made at all?"

Yet, I do not mean to pretend that the principle of contextualism leaves us with no difficulties in practice. On the contrary, it allows us to become clearly aware of just how serious the difficulties are. Competent critics disagree sharply among themselves. The ideal context is as difficult to achieve as ideals usually are. But it is not true that from the nature of the case the ideal is a hopeless one. Beauty and obscenity alike are in the eye of the beholder. But if-as artists, critics, and lovers of the arts, not as censors-we are prepared to enter into interpretation and evaluation in the one case, why not in the other?

\section{II}

Contextualism has brought us to the position that obscenity may be an objective property of a work of art, provided that the work itself be recognized as being relative to some context of response to the art object. Now many people deny that obscenity is an attribute even of the work of art, localizing it instead in the mind of the artist, by way of his "intention." But what are we to understand by artistic "intention?" Are there not different sorts of answers appropriate to the question why a particular art object was created?

We may answer, first, in terms of the artist's motive: money or glory or whatever ends external to his efforts he expected to be served by them. The legal judgment of obscenity sometimes considers motive-apparently, a work is more likely to be obscene if the artist expected to make money from his labors. But plainly, motive as such is completely irrelevant esthetically. A poet may write to pay for his mother's funeral (Johnson's Rasselas) or to seduce a woman who reminds him of his mother, but neither motive has much to do with what he writes. 
Second, artistic "intention" may be construed as purpose: a specification in terms of the artist's medium of how his motive is expressed. The purpose may be to satirize the clergy, to expose the madness of chivalric romance, or to proclaim the rights of woman. Unquestionably, purpose must be conceded an esthetic relevance -it is what the artist tried to do in his work, not by it. Many artists accused of obscenity have defended themselves by insisting on their moral purpose.

But more important than what the artist tried to do is what in fact he did do, and this may be taken as a third sense of "intention"- the intent of the work itself. A specification of purpose may define an esthetic genre, but never a particular work of art. Every work has its own unique intent: the purpose as embodied in its own specific substance. When Judge Woolsey speaks of Joyce's not "exploiting" obscenity, he is referring to Joyce's artistic purpose, perhaps also to his lack of a monetary motive. $^{8}$ But when he refers to the absence of "the leer of the sensualist," it is intent which is involved. "What is at question is as much an experienced quality of the work as is the "ring" of sincerity, which is to be contrasted with sincerity itself-the latter being a matter of motive and purpose but not of intent.

Motive, then, helps localize obscenity only in so far as it determines purpose, and the latter, in turn, only as it is embodied in intent. But this brings us back once more from the mind of the artist to the perceived characters of the work of art itself.

The alternative remains to be considered of localizing obscenity in the mind of the audience, i.e., in the effect of the work. The obscene, in the classic legal conception, is what tends to corrupt. This criterion is thought to be more "objective" than reference to the artist's intention. But such reference, at least in the sense of intent, is inescapably involved in the criterion. For the effect might otherwise have been the result of a purely projective interpretation, in which case it is not that work which is being judged to be obscene. To resort to the effect of the work is to commit oneself to distinguishing between its causal agency and its operation as a trigger mechanism, i.e., as providing an occasion for projecting onto itself a corruption already present in the reader.

Plainly, which context is selected becomes crucial. The courts may choose as standard context Judge Woolsey's "l'homme moyen sensuel,"10 but unless this standard is carefully specified (by Dr. Kinsey?), there is the serious danger that it will be replaced unwittingly by the personal context of the man passing judgment. To compare it with the standard of "the reasonable man" in the law of torts is to overlook the fact that "reasonableness" can, in principle, be intersubjectively specified (at least in part) -in terms of probabilities and their logical consequences. But where is the logic of sexual sensitivity that corresponds to the "reasonableness" of inductive and deductive inference? This question is especially em-

${ }^{8}$ United States v. One Book Called "Ulysses," 5 F. Supp. 182, 183 (S.D.N.Y. 1933), aff'd, 72 F.2d 705 (2d Cir. 1934) (the court's decision is reprinted as a preface in James Joyce, Ulisses (Random House ed. 1934)).

${ }^{\circ} \mathrm{Id}$. at $\mathrm{I} 83$.

${ }^{10} \mathrm{Id}$. at 184 . 
barrassing in view of the claim sometimes made that "familiarity with obscenity blunts the sensibilities,"11 so that on the criterion of effect, the standard context invites a circular argument: the work is obscene because it would produce the effect if only it were not such familiar obscenity!

In the ideal context, the test of effect is wholly inapplicable. For the esthetic experience requires a kind of disinterest or detachment, a "psychic distance," which is incompatible with the corruption in question. Only when we hold the work of art at arm's length is it artistic at all. The work brings emotions to mind or presents them for contemplation. When they are actually felt, we have overstepped the bounds of art. Sad music does not make us literally sad. On the contrary, the more vividly and clearly we apprehend the specific quality of "sadness" of the music, the less sorrowful our own emotions. Of course, art evokes feeling; but it is imagined feeling, not what is actually felt as a quality of what we do and undergo. And art works against the translation of imagined feeling into action. It does so partly by providing us insight into feeling, and so allowing us to subject passion to the control of the understanding, as was urged by Spinoza $;^{12}$ and partly by providing a catharsis or sublimation of feeling, as in the conceptions of Aristotle and Freud.13 In short, "there is a high breathlessness about beauty that cancels lust," as Santayana put it. ${ }^{14}$ To be sure, the extreme of psychic distance is also incompatible with esthetic experience, as in the case of the intellectual or-what is more to the point-the philistine. But to ignore altogether the role of distance is to confuse art with promotion-advertising or propaganda.

Now pornography is promotional: it is the obscene responded to with minimal psychic distance. Fundamentally, therefore, it is a category of effect. To say that a work is pornographic is to say something about the feelings and actions which it produces in its respondents. We may, of course, identify it by its purpose rather than by direct observation of effect. Its motive-monetary or sexual or whatever-it is likely to share with most art. But as to esthetic intent, this is lacking altogether in so far as the object is being read as pornographic. For in this case, it is not itself the object of an experience, esthetic or any other, but rather a stimulus to an experience not focussed on it. It serves to elicit not the imaginative contemplation of an expressive substance, but rather the release in fantasy of a compelling impulse.

Pornography as such, therefore, is no more esthetic than is an object of sentiment, which has no intrinsic interest but is responded to by way of associations external to its own substance, though not external to the references it contains (as in the words "Souvenir of San Francisco" on the bottom of the tasteless ashtray). But though the pornographic as such is never artistic, contextualism warns us that an art object in a particular context-like that of the schoolboy with the Venus-may

\footnotetext{
11 United States v. Harmon, 45 Fed. 414, 423 (D. Kan. I891).

19 See Benedictus Spinoza, Ethics passim.

${ }^{13}$ See The Poetics of Aristotle passim; Sigmund Freud, A General Introduction to PsychoANALYSIS 327-28 (I938).

I4 George Santayana, Reason in ARt ryi (1934).
} 
serve pornographically rather than as a basis for cooperation with the artist in creating a work of art. Indeed, the converse is also possible: a Pompeian wall-painting or a Central American sculpture may have been deliberately produced as pornographic but may constitute for us a work of art. In our culture, pornography masquerades as art with sufficient frequency to deserve a special designation-I suggest erotica. It is a species of what artists call "kitch": the vulgarities that hide behind a label of Art with a capital "A." Erotica consists of works that lack even the decency of being honestly pornographic.

The distinctions among these categories, however, have been made here on only the conceptual level. As a matter of fact, little is known concerning the actual effects-either stimulation or sublimation-which can be produced by words and pictures. But when obscenity is distinguished from pornography by reference to effect, it follows that art as such is never pornographic (though it may be obscene and in several senses is very likely to be). The effect of art on life is not so specific and immediate as is comprised in the concept of pornography. Action flows from impulses, habits, and predispositions which are not so easily changed as puritans both fear and hope. At most, an art object might trigger a process already primed. But in so far as this is its manner of working, it ceases to be art.

Obscenity, then, so far as it relates to art, can be localized neither in intention nor in effect, but only in the expressive substance of the work of art itself. Ultimately, to be sure, the content of a work of art, as of any vehicle of communication, is an abstraction from both intention and effect. Whether a word is insulting depends, at bottom, on its being used in order to convey an insult and its being responded to as conveying one. Yet, when this usage is established, the word is insulting even when spoken in innocence or to an insensible hearer; it has been misused or misunderstood, that is all. The question is one of the ideal context of its occurrence, not the personal context, nor yet a standard context selected to serve some extraneous interest.

I do not mean to say that obscenity is a matter of the occurrence of "dirty words." On the contrary! It is the work as a whole which must be considered. For it is an important characteristic of a work of art that it cannot be interpreted piece-meal. Each element affects the content of all the others. The work is an integrated, coherent whole whose expressive quality cannot be additively constructed from what is expressed by its isolated parts. Judge Woolsey's position is esthetically unassailable when he says of Ulysses that, although it contains "many words usually considered dirty.... Each word of the book contributes like a bit of mosaic to the detail of the picture which Joyce is seeking to construct for his readers." ${ }^{15}$ Indeed, isolated words may easily lose their expressiveness by mechanical repetition, to be restored to artistic potency only by skillful exploitation of a fresh setting in a com-

${ }^{15}$ United States v. One Book Called "Ulysscs," 2 F. Supp. 182, 184 (S.D.N.Y. 1933), aff'd. 72 F.2d 705 (2d Cir. 1934). See also James T. Farrell, Testimony on Censorship, in Reflections at FifTY 212 (1954). 
plex work. The obscenity that occurs in a work of art may be as shocking to some as army talk; but it is wholly different in quality. The one is expressive; the other marks both the failure of expression and the lack of something to express.

It is a further consequence of this conception that obscenity in art not only does. not lie in a baldness of sexual reference, but is, in fact, incompatible with wholly explicit statement. Explicitness may be pornographic, but it has no place in art. Where nothing is left to the imagination, the reading of the art object may stimulate an experience but does not itself constitute one. No opportunity is provided for that sharing in the act of creation which alone makes an experience esthetic. Nothing is a work of art for me unless I have been able to put something of my deeper self into it. The art object invites me to express something of that self and guides me in my efforts to do so; but the effort must be mine. Hence the popularity of the merely pornographic: it makes so few demands. Genuine expression is replaced by a' spurious consummation.

As an esthetic category, obscenity is, by contrast, of the very stuff of imagination. In one etymology, "obscene" is from "obscurus"-what is concealed. Now expression is concealment as well as revelation. Art speaks in symbols, and at the core of every symbol is a secret which only imagination can fathom. The symbol itself thus takes on the mysterious quality of what it hides. It is experienced as charged with feeling and produces tension by at once inviting and resisting penetration. Both art and obscenity have a single genetic root: the infantile capacity to endow a mere sign with the affect that belongs properly to what it signifies. ${ }^{10}$ A creature incapable of obscenity is also incapable of art. Magic, too, avails itself of the same capacity: words themselves become things, imbued with mysterious powers over other things. Psychologically, obscenity stands between art and magic-neither wholly makebelieve like the one, nor yet wholly believing like the other. In many cultures, obscenity has an important role in magical rituals. In our own, its magical character is betrayed in the puritan's supposition that words alone can work evil, and that evil will be averted if only the words are not uttered.

III

Because there is, after all, a difference between a symbol and what it symbolizes, obscenity is a matter, not of what the work refers to, but rather of the expressive substance of the work. Puritans may condemn a work for presenting certain aspects of life; artists may defend it because what is presented are certain aspects of life. Truth is used both as a mark of obscenity and as a mark of its absence. In fact, it can serve as neither. The question whether the world is as art (referentially) presents it to be is irrelevant to esthetic quality in general, and to the quality of obscenity in particular. Art is not obscene by virtue merely of its subject, nor does it cease to be obscene merely because its subject is virtuous. A verse attributed to $D$. $H$. Lawrence complains, "Tell me what's wrong with words or with you, that the thing

\footnotetext{
${ }^{16}$ See Sandor Ferenczi, On Obscene Words, in Sex in̉ Psychoanalysis c. 4 (1950).
} 
is all right but the word is taboo!" But there is nothing wrong with recognizing that words and things are different, and that properties of the one cannot necessarily be imputed to the other. Words are public, for instance, and easy to produce, and can occur in contexts where the things they refer to would not be appropriate and could not occur. The Stoics argued that "there being nothing dishonest in the conjugal duty, it could not be denoted by any dishonest word, and that therefore the word used by clowns to denote it is as good as any other."17 The question is, however, whether clowning is not different from conjugal life as the Stoics themselves conceived it, and whether the language used is not in fact part of the clowning.

In short, obscenity, like art itself, is not a matter of referential, but of expressive meanings. What is relevant is not subject, but substance; not an isolable message, but an embodied content. The artist does not bodily translate a subject into the work, but transforms it-he selects from it and gives it form. Thereby the work becomes more than merely an instrument of communication; it commands intrinsic interest because of its own inherent qualities. No subject as such can be obscene (one can always talk about it in Latin!). To be sure, the subject of a work of art contributes to its substance-reference enters into the service of expression-and so has an indirect relevance. ${ }^{18}$ But the indirectness is crucial. A sexual subject (or similar reference) is a necessary condition for obscenity but not a sufficient one; only for pornography, as for propaganda, does the referential message suffice.

Thus, though censorship may extend to themes as well as treatments, obscenity does not. The immorality of the actual characters and conduct which provide the novelist with his material is alike irrelevant to the charge of obscenity and to the defense against it. For words are not the things they mean; art is not life. Art supplements life and does not merely duplicate it. The question of obscenity is a question of what the novelist is bringing on the scene, and the first answer to that question must be "a novel"; a sequence of incidents with form and expression. The qualities of the work are not determined by the traits of its subject matter. Truth, therefore, in the sense of depicting life as it is, neither produces nor precludes obscenity.

\section{IV}

Obscenity, then, is an experienced quality of the work of art and can no more be localized in the subject matter of the work than in its intention or effect. But what quality is it? There are, in fact, several species of the obscene, which must be distinguished from one another because they differ so widely in their esthetic status and function.

First, is what I call conventional obscenity: the quality of any work which attacks established sexual patterns and practices. In essence, it is the presentation of a sexual heterodoxy, a rejection of accepted standards of sexual behavior. Zola, Ibsen, and

\footnotetext{
${ }^{17}$ Pierre Bayle, The Dictionary Historical and Critical 850 (1837).

${ }^{18}$ See Kaplan, Referential Meaning in the Arts, 12 J. Aesthetics and Art Crimcism 457 (1954).
} 
Shaw provide familiar examples. The accusations of obscenity directed against them can be seen clearly-in retrospect!-to have been social rather than moral. The guilt with which they were charged was not sin, but a violation of good taste and, even more, of sound judgment. For sexual heterodoxy is frequently generalized, by the writer and his readers alike, to an over-all radicalism. To attack established morality in any respect is to undermine the authority of every established pattern. It surprises no one that the author of Nana also wrote l'Accuse; of Ghosts, An Enemy of the People; and of Mrs. Warren's Profession, Saint Joan. It is a commonplace that mores tend everywhere to be moralized, so that unconventionality of any kind is condemned as immoral, and if sexual, as obscene.

The dual vocabulary for sexual subject-matters, to be found in many cultures besides our own, is a device to preserve the conventions. The four-letter word is a scapegoat which allows the rest of the language to be free of $\sin .^{10}$ The use of a foreign language (especially Latin) for questionable passages conveys a detached point of view which leaves the conventions undisturbed. More important, the foreignness restricts the work to a well-educated elite, whose conformity is not in doubt or who may, indeed, feel privileged to stand above the mores altogether. Conventional obscenity is not too good for the masses. It is too dangerous for them. If they begin by attacking accepted standards of sexual behavior, so the theory runs, they will end by rejecting all social constraints in an orgy of anarchic egoism.

Accordingly, it is conventional obscenity which is the main concern of the censor -not, say, the pornography of night-club entertainment. From the viewpoint of the censor, the tired business-man may call "time-out," but he mustn't change the rules of the game. It is one thing for him to declare a moratorium on his debt to society, but quite another for him to repudiate his honorable obligations. In short, he may be wicked but not scandalous; and scandal consists in open revolt against sexual constraints rather than covert evasion of them. Pope Paul IV was consistent in expurgating Boccaccio by retaining the episodes but transforming the erring nuns and monks into laymen: $:^{20}$ thereby scandal was averted.

Now it might appear that conventional obscenity has nothing to do with art as such, but only with propaganda. For a work is usually identified as conventionally obscene on the basis of its message, not its expressive content; and art does not convey messages. As Sidney long ago pointed out in his defense of poesie, ${ }^{21}$ the poet does not lie because he asserts nothing. He therefore does not assert that sexual conventions must be changed, but at most presents for imaginative contemplation the workings of our or other conventions. Some artists, however, consciously adopt a propagandistic stance. Yet, conventional obscenity does not depend upon a literalistic approach to art by way of subject, reference, and message rather than substance, expression, and embodied meaning. Both puritan and propagandist over-

\footnotetext{
${ }^{10}$ See Read, An Obscenity Symbol, 9 AMERICAN SPEech 264, 267 (1934).

${ }^{20}$ See A. L. Haight, BanNed Books 8 (1935).

${ }^{21}$ Philip Sidney, The Defence of Poeste.
} 
look the more subtle morality in the content of a work of art, in terms of which conventional obscenity is not limited to a reformist purpose, but plays an important role in all artistic intent.

The artist's integrity requires that he present the world as he sees it; his creativity, that he see it afresh, in his own terms. The new vision is bound to be different, and as different, is judged to be wicked by the conformist morality of the old. The Hays production code requires that "correct standards of life" be presented, "subject only to the requirements of drama and entertainment"! But if they are subjected also to the requirements of honest and creative art, their "correctness" is likely to be challenged. Again and again in the history of art, the creative artist has had to take his stand against the Academy, as the repository of tradition not merely in art, but in life as well. Clive Bell is scarcely exaggerating when he warns that "of all the enemies of art, culture is perhaps the most dangerous."22 "The academic artist is likely to be free of conventional obscenity, but also to be innocent of esthetic quality. The artist who creates new forms and exploits new techniques-who develops, in a word, a new style-does so because he has something new to say; and in art, whatever is said needs its own language. The very newness is then felt as an attack on established patterns. The hostility to "modern art" evinced by the pillars of church, state, and society is not a product of insensitivity. On the contrary, it displays a realistic awareness of the threat which art has always posed to sheer conformity. The charge of obscenity directed against the arts is strictly comparable to the moral depravity regularly ascribed to heretical religious sects. "Thou shalt have no other Gods before me!" and a new vision of God-so says the priesthood-can only be a visitation of the Devil.

Art, in short, is a matter of inspiration as well as of skill. And inspiration-from the standpoint of the conventional-is a demonic corruption of the old rather than a new revelation of the divine. The "genius" is one who is possessed and hence dangerous. Mann's Faustus embodies a recurrent myth of the artist: he has sold his soul to the Devil to enjoy the fruits of the sin of hubris committed in imitating the Creator. A vicious circle is thus engendered. The philistine distrust of the artist leads to his rejection by established society, which provokes a counter-attack that in turn is taken to justify the initial reaction. The situation, then, is not that we can generalize from sexual heterodoxy to a wholesale radicalism. It is rather that we can particularize from the artist's rejection of convention-because for him it is stale, flat, and unprofitable-to a sexual heterodoxy, and thus to conventional obscenity. The representation of pubic hair, for instance, is commonly regarded as obscene. But this is largely because it did not appear in the classic nude; and it did not appear there because the prevailing custom was to remove the hair from the body. ${ }^{23}$ This is not our custom; but it is the custom in our art, and to depart from it is, therefore, to be obscene.

${ }^{22}$ CLIVE BeLL, ART 267 (I927).

${ }^{23}$ Sec 4 Havelock Exlis, Studies in the Psychology of SeX 94 (1936). 
Now it is easy to exaggerate the danger to established patterns from art. We have already seen that there is no ground for supposing the effect of art on life to be immediate and direct. On the other hand, it is easy to exaggerate also the contribution to society which conventional obscenity makes. Traditional morality may be sound even if conformist, and in many respects surely is sound. Society needs stability as well as change; some changes are for the worse. Stability cannot be identified with stagnation and death, as Herbert Read has rashly claimed in defense of the artists as advocati diaboli. ${ }^{24}$ The part of reason, it seems to me, is to reject both the sterile conformism which condemns art for its conventional obscenity and the destructive individualism which takes pride in standing above "the law of the herd."

\section{$\mathrm{V}$}

A second type of obscenity I call Dionysian obscenity. It consists in what society regards as "excessive" sexualism. Familiar examples are provided by Aristophanes, Boccaccio, Rabelais, and the Elizabethans. As a quality of the work of art, it is an expression of an exuberant delight in life. Dionysian obscenity is present in its clearest form in the old Greek comedy where its connection with fertility rites and phallic ceremonies is obvious. It has played a part in such rites and ceremonies in many cultures.

Its occurrence in art forms is equally widespread. For art rests above all on a delight in color, sound, texture, and shape. The appeal of art is first sensuous; and between the sensuous and sensual the difference is only in the suffix not the root. The art object presents for enjoyment an esthetic surface in which formal and expressive values are present, to be sure, but only as fused with an immediate sensory appeal. The work of art may lead us, as Plato and Plotinus hoped, ${ }^{25}$ to the world beyond sense; but it can do so only through sense. And sense must delight us in the passage. This fact was at the bottom of the iconoclastic controversy and has led some strict puritans to condemn all art as essentially immoral. The premise from which the condemnation springs is a sound one, even if the conclusion is not. We cannot consistently worship beauty and despise the pleasures which the bodily senses can afford. Matthew Arnold was distressed at the "vulgarity" of some of Keats' letters to Fanny Brawne; but more realistic critics have recognized that if he were incapable of such letters, he would not have written The Eve of St. Agnes. ${ }^{20} \mathrm{Di}$ onysian obscenity in art is of a piece with the enthusiasm which the artist displays over the delightful qualities of his medium.

But the artist is not merely celebrating the joys of esthetic perception. He is also providing a symbolic consummation for the entire range of human desire. It is the artist who can truly say that, being human, nothing human is alien to him. He is

\footnotetext{
24 See Marjorie Bowen, Ethics in Modern Art ix (1939).

${ }^{25}$ See The Symposium of Plato passim; Plotinus, ON the One and Good, neing the treattses OF THE SIXTH ENNEAD passim.

${ }^{28}$ E.g., BELL, op. cit. supra note 22 , at $27 \mathrm{I}-72$.
} 
forever drawing the circle which takes in what man and nature reject. He himself is wounded by such rejection, and in comforting himself he pleases everyone. It is scarcely accidental that so much art, in all cultures and in all media, has to do with love. The human interest of love, in all its phases and manifestations, is the inexhaustible riches from which art unceasingly draws beauty. Can anyone doubt that if the human mammal gave birth in litters, painters and sculptors would find in multiple breasts the exquisite forms that the female nude now provides them? Whatever art touches it transfigures. But though the poet makes of love the divine passion, it remains passion. And when he presents it for what it is, in its fullbodied vigor, we call him obscene.

Whatever else art may be, it is an intensification of emotion. And when the emotion is a sexual one, the result is Dionysian obscenity. It cannot be pretended that the poetry, painting, sculpture, and even music of love owe nothing and repay nothing to our sexuality. We may recognize this debt without reducing beauty altogether to an effusion of sex. But art is not confined to the bare surface of human feeling. It enriches experiences only because its roots penetrate to the depths of feeling and so bring our emotional life to flower.

The consummations of art, however, are symbolic. It is for this reason that "excessive" sexuality so often finds a place in art: there is no other place for it to go. The symbol is possible when the reality is not. Dionysian obscenity is a symbolic release of impulses thwarted in fact. It compensates us for the frustrations imposed by rigid conventions. It is not merely a device to elude external repression; it is a mechanism whereby we can admit our feelings to ourselves. Sex becomes permissible when it is esthetically symbolized. We condemn it as obscene only when being brought face to face with our own impulses overwhelms us with anxiety and guilt.

On this basis, Dionysian obscenity not only need not be immoral, but may even serve as a moral agent. By providing a catharsis or sublimation, art may act as a safety-valve without which libidinal pressures become explosive. This is especially suggested by the comic quality so characteristic of Dionysian obscenity. Modern bürlesque, from a historical viewpoint, is a pathetic attempt to recapture this quality. Comedy releases in laughter tensions which might otherwise prove no laughing matter. The comic spirit detaches us from our impulses and their frustration to allow a satisfaction on another level.

It is for this reason, too, that Dionysian obscenity is so seldom pornographic. Pornography is grim and earnest and feeds only on frustration. In art, sexual energies are not gathered up for a desperate assault on social restraints, but are canalized so as to structure an esthetic experience which is in itself deeply satisfying.

The protest against Dionysian obscenity is essentially a protest against sexuality as such. It is a denunciation of the innate depravity of human nature, which finds satisfaction in "the lure of the senses and the evils of the flesh." The Dionysian, on the other hand, refuses to regard the act of love as inherently sinful. On the con- 
trary, for him it is the supreme manifestation of what is good in life: the indomitable creative impulse. This same impulse finds expression in art. In Dionysian obscenity, art and life join in vigorous, unrestrained laughter.

\section{VI}

Completely different in quality is a third kind of obscenity, which I call the obscenity of the perverse. Unlike conventional obscenity, it is not an attack on accepted standards, nor is it, like Dionysian obscenity, an affirmation of impulse despite restraints. It is rather a rebellion against convention which at the same time acknowledges the authority of received standards. In the obscenity of the perverse, the artist "accepts the common code only to flout it; conscious of sin, he makes sin attractive; his theme is 'the flowers of evil.' "27 Baudelaire himself, as he claimed, does make sin hideous. The truly perverse finds sin attractive because it is $\sin (e . g$., Huysmans, de Sade). His obscenity lacks the naiveté of the Dionysian; it is likely to be lewd in a sophisticated fashion. The effect is that of calculated indecency.

Dionysian obscenity celebrates sex; conventional obscenity is neutral towards sex, being concerned primarily with the social evils of particular sex patterns; for perverse obscenity, sex is dirty, and it occupies itself with sex for the sake of the dirt. In viewing all obscenity as "smut" and "filth," the puritan only betrays his own perversion. There is here a profound ambivalence, a rebellion which is also a submission. Satan is not a free spirit, but a rebel divided against himself. In freedom, there is a vigor and forthrightness, an enlargement of the soul, which is the antithesis of evil. In perverse obscenity, we have the pathetic spectacle of the Black Mass-worshippers without a God, seeking in hatred and rejection what they are incapable of accepting in love.

At bottom, the obscenity of the perverse is sheer hypocrisy: it is not so black as it paints itself. While pretending to rise above morality, it abjectly submits to it and only thereby becomes truly immoral, in playing false to its own dignity and freedom. While pretending to delight in sex, in fact it abhors sexuality, beng convinced of its sinfulness and seeking it out only for the sin. For the perverse, sex is desirable only because it is forbidden; but it remains in the end a bitter fruit. Paradoxically, it is the puritan who creates such obscenity. For its foundation is secrecy and shame. The obscene is what is off the scene, hidden, covered. And shame, as ethnologists have long recognized, is not merely the cause of covering, but the effect. ${ }^{28}$ The secret becomes shameful because of its secrecy. To be perverse is to uncover it merely because it is hidden. This is the obscenity of the leer and innuendo. The asterisks and dashes of the supposed puritan serve in fact to convey unambiguously the perverse content.

Basically, what perverse obscenity expresses is fear-fear of the great power of the sexual impulses. It is because of this power that prohibitions and constraints

\footnotetext{
${ }^{27}$ Aldert Guírard, Art for Art's Sake i $89-90$ (1936).

${ }^{28}$ Sec, e.g., Edward Westermarcx, The History of Human Marriage 21 ( (3d ed. 1901).
} 
have been imposed upon it in all societies. But just because it is hidden, it looms larger and more threatening. What is perverse is not the concern with being overwhelmed by brute desire; it is the part of reason to look to the defenses of rationality. The perversion consists in purchasing freedom from anxiety by assuming a burden of guilt, selling one's soul to the Devil for fear of being rejected by God. Perverse obscenity tries to cope with the forces of sexuality by a symbolic denial of their potency. It plays with fire in a childish effort to convince itself it cannot be burned. But what is most manifest in it is only the futility and the fear. By contrast, Dionysian obscenity triumphs over impulse by freely yielding to it, while conventional obscenity resolutely sets itself to canalize impulse more effectively than custom permits.

There is thus a close connection between the obscenity of the perverse and blasphemy. Historically, indeed, it was only on the basis of this connection that the early strictures against obscenity proceeded. ${ }^{29}$ The obscenity of the perverse simultaneously makes too much of sex and too little; just as the blasphemer acknowledges God by denying Him, profanes the holy to damn himself. Diabolism, after all, is just another religion. Perverse obscenity does not wish to profane love in order to remove the taboo from it. Just the contrary: it pretends to ignore the taboo so as to destroy what is, for it, the fearful holiness of love. It is perverse obscenity, not the Dionysian, which is likely to be exploited in pornography; for pornography, as D. H. Lawrence has noted, is "the attempt to insult sex, to do dirt on it."30 In the obscenity of the perverse, sex is no more than a disgusting necessity; the perversion lies in finding pleasure in the disgust.

Such an attitude is plainly foreign to art and could enter into esthetic experience only to drain it completely of esthetic quality. It is approximated, however, by a type of obscenity which lies between the Dionysian and the perverse-what might be called romantic obscenity. This is the category, exemplified in Swinburne and the "fleshly" school, which preserves the sense of sin yet celebrates sexuality in spite of it. It lacks the pagan innocence of the Dionysian but also the lust for evil of the perverse. It is romantic, as expressing a felt need to cover the nakedness of sex with sentiment and estheticism. This need is nowhere more apparent than in the strident insistence on being unashamedly sensual. The art in which romantic obscenity is to be found has something of the pathos of adolescent bravado.

VII

In one of its etymologies, the word "obscene" is given the sense of inauspicious and ill-omened. ${ }^{31}$ This is the sense appropriate to the obscenity of the perverse, for its content is hate, not love. It seeks in sexuality only what is life-denying, finding in sinfulness the great Nay which it struggles to express. Its impulse is to destroy itself,

\footnotetext{
${ }^{20}$ See, e.g., Alpert, Judicial Censorship of Obscene Literature, 52 Harv. L. Rev. 40, $43-44$ (1938).

${ }^{30}$ D. H. LAWRENCE, op. cit. supra note 6 , at 74 .

${ }^{32}$ See Havelock Ellis, The Revaluation of Obscenity, in More Essays of Love and Virtue 99
} (I931). 
though it contents itself with a stylized gesture towards the self-castration which some fathers of the church performed in fact. Obscenity may thus become linked with symbols of violence.

Aggression is as much repressed and controlled by society as are libidinal impulses. Murder is as universally condemned as incest, hostility as rigidly patterned as sexuality. Aggressive impulses, therefore, also seek expression in the symbols of art. Corresponding to the sexuality of Dionysian comedy is the violence of Greek tragedy. The impulses of love and hate may become confused and intertwined and sex patterned into sado-masochistic perversion. In the expression of this content, psychic distance can no longer be maintained, but is submerged in empathic identifications both with brutality and with its victims. A new category of the obscene emerges: the pornography of violence.

In this type of obscenity, sexual desires find symbolic release only as transformed into acts of aggression. ${ }^{32}$ A phenomenally popular series of novels is constructed according to a rigid pattern of alternation of violence and sex which coincide only at the climax when the virile hero is allowed to shoot the wicked beauty. More sophisticated in style and structure, but essentially the same in substance, is the work of the "realistic" school sometimes associated with the name of Hemingway. Death in the afternoon prepares for love at midnight. There is no question that writing of this genre is effective; the question is only whether the effect is esthetic-an abattoir can also provide a moving experience. Esthetic or not, this genre is enormously successful; taking into account the "detective" story and the crime "comic," the pornography of violence is more widespread in our culture than all the other categories of obscenity put together.

It is, perhaps, banal to associate this fact with the role of violence in our culture, as a source even of recreation for the spectator. Yet, Henry Miller's denunciation must be taken seriously: "Fear, guilt and murder-these constitute the real triumvirate which rules our lives. What is obscene then? The whole fabric of life as we know it today." ${ }^{33}$ It is easy to dismiss so sweeping a judgment. Yet, it remains true that the pornography of violence enjoys an immunity denied altogether not only to Dionysian obscenity, but even to the fundamentally respectable conventional obscenity. A noteworthy exception is the action of the British Board of Film Censors in prohibiting the showing of Disney's Snow White to children, on the ground that it might frighten them, at a time when all the children in London were being taught how to wear gas-masks. ${ }^{34}$

\section{VIII}

Moral issues, as such, fall outside the scope of this essay. Yet, esthetics cannot

${ }^{32}$ See generally Gershon Legman, Love and Death (1949); George Orwell, Raffles and Miss Blandish, in Critrcal Essays I42 (1946).

${ }^{33}$ Miller, Obscenity and the Law of Reflection, Tricolor, Feb. 1945, p. 48, reprinted in HenRY MrLler, The Air-Conditioned Nightmare (vol. 2, Remember to Remember) 274, 286 (I947).

34 Sec H. L. Mencken, The American Language Supplement One 644 (1948). 
ignore the moral content of art, and the esthetics of obscenity must finally face the question of how obscenity, in its various species, affects that content.

The moral content of art is plainly not a matter of doctrinaire messages, but something more fundamental. As I conceive it, it is nothing less than the affirmation of life, a great yea-saying to the human condition. In mastering its medium and imposing form on its materials, art creates a microcosm in which everything is significant and everything is of value, the perfection of what experience in the macrocosm might be made to provide. In this capacity, art may serve as the voice of prophecy and, like all prophets, go unheard or be stoned when its teaching is at variance with a law no longer alive to the demands of life. If, as in literature, human life itself is the subject to be artistically transformed, art insists on seeing it whole, for only thus can it understand and revitalize it; but when art uncovers what men wish to keep hidden, it is despised and condemned. And always, art remains a challenge to evil and death, forcing enduring human value out of the sadly deficient and evanescent material of experience.

In this conception, conventional and Dionysian obscenity, and perhaps also romantic obscenity, all play their part in the performance of the esthetic function; but not pornography, not the obscenity of the perverse, and especially not the pornography of violence. For these are in the service of death, not of life. They belong to that monstrous morality and taste of the burial-ground where death is glorified and the sculpture of Michelangelo is given a fig leaf. The god of such obscenity is not Eros, but Thanatos. Not the wages of sin, but sin itself, is death. 